\title{
Detection of COVID-19 in tears of ICU-admitted patients with SARS-CoV-2 infection
}

\author{
Seyed Hashem Daryabari • Atieh Asadollah · Farhad Adhami Moghadam • \\ Ruhollah Dorostkar · Ali Bahramifar · Hossein Aghamollaei
}

Received: 6 November 2020/Accepted: 18 June 2021/Published online: 11 November 2021

(C) The Author(s), under exclusive licence to Springer Nature B.V. 2021

\begin{abstract}
Purpose Upon the outbreak of 2019, novel coronavirus (COVID-19) pandemic confirmed the cases surpassed 20 million. Despite a few reports identified the association of severe acute respiratory syndrome coronavirus 2 (SARS-CoV-2) with ocular manifestations, it may assess the ocular symptoms of patients with the COVID-19 by ophthalmologists facilitate the diagnosis and prevent transmission.

Methods A total of 60 patients with the COVID-19 admitted to Baghiatallah hospital from March 2020 to May 2020 were retrospectively reviewed and analyzed for the ocular manifestations, blood tests, and reverse transcriptase-polymerase chain reaction (RT-PCR) for SARS-CoV-2 using nasopharyngeal and conjunctival swabs.

Results Among 60 included patients with clinically confirmed COVID-19, the median age 58.36 years (IQR: 30-88 years), 27 (45\%) were male. Furthermore, $29(48 \%)$ and $5(8 \%)$ patients yielded positive for SARS-CoV-2 on RT-PCR from nasopharyngeal swabs and conjunctival specimens, respectively. Among 60 patients, $10(16 \%)$ and $3(5 \%)$, respectively, had the ocular manifestations and positive
\end{abstract}

S. H. Daryabari $(\bowtie) \cdot$ A. Asadollah .

F. A. Moghadam - R. Dorostkar - A. Bahramifar .

H. Aghamollaei

Baghiatollah University of Medical Sciences, Tehran,

Islamic Republic of Iran

e-mail: shdarya50@yahoo.com results for SARS-CoV-2 on RT-PCR from conjunctival and nasopharyngeal swabs.

Conclusion Although the positive rate of tear RTPCR rate is not noticeable as nasopharyngeal swabs yet, COVID-19 transmission through the eyes is biologically plausible.

Keywords COVID-19 - Nasopharyngeal RT-PCR · Tear RT-PCR · Ocular manifestation

\section{Introduction}

At first, in December 2019 in Wuhan, China, severe acute respiratory syndrome coronavirus 2 (SARS$\mathrm{CoV}-2$ ) was identified [1]. SARS-CoV-2 is a member of beta coronavirus genus [2] with an enveloped single-stranded positive-sense RNA virus [3]. Following the rapid spread of SARS-CoV-2 around the world, the disease became a global health threat, and a pandemic was announced by World Health Organization (WHO), which is called 2019 novel coronavirus (COVID-19) [4].

The COVID-19 is so contagious and a broad spectrum of clinical features developed in patients, from fever and cough to acute respiratory symptoms [5]. Severe respiratory failure is the leading cause of death in these patients, so much of the research on COVID-19 is related to the respiratory system. Despite knowing more about COVID-19, this disease 
should be investigated in other organs because each organ may illustrate a transmission method [6].

The COVID-19, like SARS-CoV, gets cell entry via the angiotensin-converting enzyme (ACE2), a ubiquitous cell surface receptor found in the conjunctiva. Few studies verified SARS-CoV-2 presence in tears [7, 8]. In Wuhan, China, the death of an ophthalmologist infected with unilateral conjunctivitis has signified disease transmission probability through the eyes. An additional report indicated the clinical diagnostic significance of conjunctival congestion, all health care workers having close contact with infected patients urged to use the eye shields $[9,10]$. We evaluated SARS-CoV-2 presence in the tears of clinically confirmed COVID-19 cases.

\section{Methods}

About 60 samples were obtained from the patients with the COVID-19 admitted to Baghiatallah hospital in the infectious ward and intensive care unit (ICU) from March 2020 to May 2020. The written informed consent form received from all study participants. This study was done following the Helsinki Declaration and institutional ethics committee approval. The criteria for clinical diagnosis and entering the study followed the Iranian national guideline based on a) radiological findings such as ground glass appearance and alveolar infiltration, b) clinical symptoms, c) positive nasopharyngeal RT-PCR swab test for COVID-19 infection [11].

Nasopharyngeal RT-PCR was performed at the time of hospitalization, and tear RT-PCR was done on the first day in the admitted patients to the ward and up to 2 days in the ICU patients. Following the WHO protocols for the nasopharyngeal sampling, the dry cotton or synthetic fiber swab is used. An ophthalmologist (S.H.D) collected all tear samples. The disposable swabs were used to collect the tear samples. It was placed in the lower fornix of each eye without topical anesthesia for $10 \mathrm{~s}$, and the secretion was sent to the virology laboratory as soon as possible in the appropriate condition. Real-Time RT-PCR Diagnostic Panel is a molecular in vitro diagnostic test which aids in detecting and diagnosing SARS-CoV-2 infection which is based on widely used nucleic acid amplification technology. The product contains the oligonucleotide primers and dual-labeled hydrolysis probes
(TaqMan ${ }^{\circledR}$ ) and control material used in RT-PCR for in vitro qualitative detection of 2019- nCoV RNA in the specimens. The oligonucleotide primers and probes for detecting 2019-nCoV RNA were selected from the regions of virus nucleocapsid $(\mathrm{N})$ gene. The panel is designed for the specific detection of SARSCoV-2 (two primers/probe sets). An additional primer/ probe set to detect the human RNase P gene (RP) in the control samples and clinical specimens is also included in the panel.

\section{Results}

A total of 60 patients with clinically and laboratoryconfirmed COVID-19 were recruited. Among 60 patients, $27(45 \%)$ were males, and $33(55 \%)$ were females with a median age of 58.36 years (IQR: $30-88$ years). Twenty-five (41.6\%) patients were ICU-admitted. Nasopharyngeal RT-PCR and tear RT-PCR yielded positive for COVID-19 in 29 (48.3\%), and 5 $(8.3 \%)$ patients, respectively. All these five patients were ICU-admitted (20\%) who had at least one comorbidity ( 2 with diabetes mellitus, 2 with hypertension, and 1 with lung disease). The concurrent positive tear and nasopharyngeal RT-PCR detected in 3 patients $(12 \%)$. We did not find any meaningful relationship between tears and nasopharyngeal swab positive rate (p-value:0.586).

Symptoms and severity

The most commonly self-reported symptoms at the onset of illness were cough and dyspnea $(n=28,46 \%)$, fever $(n=21,35 \%)$, and myalgia $(n=13,21 \%)$. Ocular symptoms and signs including red-eye, secretion, conjunctivitis, and chemosis, existed in 10 patients $(16 \%)$.

The severity of disease was scored due to CT scan findings (ground glass appearance and alveolar infiltration) and clinical symptoms to the mild, moderate, and severe [12]. Based on this scoring 15(25\%), $24(40 \%)$, and $21(35 \%)$ cases were mild, moderate, and severe, respectively. Reported comorbidities by decreasing frequency were diabetes $(n=33,55 \%)$ with 2 uncontrolled diabetes, chronic obstructive pulmonary disease $(n=4,6 \%)$, hypertension $(n=$ $18,30 \%)$, ischemic heart disease $(n=13,21 \%)$ (Table 1). 
Table 1 Demographic and clinical characteristics of the study patients

\begin{tabular}{|c|c|}
\hline Parameter & Value \\
\hline Age, median, years & 58.36 \\
\hline \multicolumn{2}{|l|}{ Sex } \\
\hline Male, $n(\%)$ & $27(45 \%)$ \\
\hline Female, $n(\%)$ & $33(55 \%)$ \\
\hline ICU patients, $n(\%)$ & $25(41.6 \%)$ \\
\hline \multicolumn{2}{|l|}{$R T-P C R$ positive } \\
\hline Tear, $n(\%)$ & $5(8.3 \%)$ \\
\hline Nasopharyngeal, $n(\%)$ & $29(48.3 \%)$ \\
\hline Both tear and nasopharyngeal, $n(\%)$ & $3(5 \%)$ \\
\hline \multicolumn{2}{|l|}{ Symptoms } \\
\hline Cough and dyspnea, $n(\%)$ & $28(46 \%)$ \\
\hline Fever, $n(\%)$ & $21(35 \%)$ \\
\hline Myalgia, $n(\%)$ & $13(21 \%)$ \\
\hline Bilateral conjunctivitis, $n(\%)$ & $3(5 \%)$ \\
\hline Chemosis, $n(\%)$ & $1(1.6)$ \\
\hline Conjunctivitis and chemosis, $n(\%)$ & $2(3.3)$ \\
\hline Allergic and hypersensitive red eye, $n(\%)$ & $4(6.6 \%)$ \\
\hline \multicolumn{2}{|l|}{ Severity } \\
\hline Mild, $n(\%)$ & $15(25 \%)$ \\
\hline Moderate, $n(\%)$ & $24(40 \%)$ \\
\hline Sever condition, $n(\%)$ & $21(35 \%)$ \\
\hline \multicolumn{2}{|l|}{ Comorbid disease } \\
\hline Diabetes, $n(\%)$ & $33(55 \%)$ \\
\hline Obstructive pulmonary, $n(\%)$ & $4(6 \%)$ \\
\hline Hypertension, $n(\%)$ & $18(30 \%)$ \\
\hline Ischemic heart disease, $n(\%)$ & $13(21 \%)$ \\
\hline
\end{tabular}

\section{Discussion}

There are overwhelming reports of COVID-19 pneumonia and practical advice to prevent viral transmission through it. However, despite several reports concerning infected ocular discharge, the exact frequency and transmission rate remained unknown. [6]. One of the hypotheses which justifies virus presence in the eye is that the ACE2 is a cellular receptor of SARS-CoV-2 and ACE2 was detected in the human retina, vascularized retinal pigment epithelium choroid, and conjunctival epithelia; ACE2 may involve in the ocular manifestation of COVID-19 and SARSCoV-2 enters into host-tissue after the combination of the viral hemagglutinin protein to ACE2 [4, 13]. Also in a study were done by Grajewski, $\mathrm{R}$ et al., demonstrated that the receptor for entry of SARSCoV-2 provide by specific ACE2 expression in conjunctival epithelial cells [14] and ACE2 is expressed in multiple organs such as the heart, lungs, kidney, intestines, buccal cavity [15]. Many health workers are at risk to get the virus through the eyes, like the Chinese ophthalmologist who for the first time claimed to infect through eye discharge, [10]; thus, more clinical studies are needed to confirm this correlation.

Since the first outbreak of COVID-19, several studies were performed, in which various ocular manifestations were reported. In a study of 67 patients by Zhou et al., the tear RT-PCR test result was positive in only one patient. The patient was one of the drivers of hospital emergency team who was in contact with the patients in the isolation ward, only with a mask, without eye protection. No ocular symptoms were observed in this patient. This report shows that an asymptomatic patient can easily transmit the infection. Furthermore, the study reported that several patients were hospital staff who did not use a shield and only wore masks and became infected [16].

In our study, we examined 60 patients, only five ocular samples were positive for tear RT-PCR (8\%), and none of them had ocular symptoms. SARS-CoV-2 presence in tears can be due to direct inoculation, virus migration from the respiratory tract via the nasolacrimal duct, or the infection of lacrimal gland and consequent shedding of virus [6] or the possibility of being exposed to the virus because of the patient's unconsciousness in ICU in its infected atmosphere. Moreover, it was postulated that the affinity of SARSCoV-2 to ACE-2 makes it possible for the virus to infect ocular tissues [8, 17].

All 5 patients were ICU-admitted, indicating that the ocular involvement with the COVID-19 could be directly related to the severity of disease and its duration. All 5 patients were in ICU for a more extended period, so the virus had longer to be transmitted to the eye. Two of these five patients were negative for the nasopharyngeal RT-PCR. This observation may be due to two reasons: (1) Throat sampling was improperly done, while an ophthalmologist performed all tear sampling, (2) Time of tear sampling. In the ICU, tear samples were taken from patients 48 to $72 \mathrm{~h}$ after pharyngeal sampling. Differences in eye and throat sampling time could cause positive results for the tear RT-PCR test following disease 
progression. Since the first outbreak of COVID-19, several studies were performed, in which various ocular manifestations have been reported. In a study of 67 patients by Zhou et al., the tear RT-PCR test result was positive in only one patient. The patient was one of the drivers of hospital emergency team who was in contact with the patients in the isolation ward, only with a mask, without eye protection. No ocular symptoms were observed in this patient. This report shows that the asymptomatic patients can easily transmit infection. Furthermore, the study reported that several patients were hospital staff who did not use a shield and only wore masks and became infected. Therefore, ICU staff are much more likely to be infected by ocular secretions because patients' eyes can have no symptoms despite a viral infection. Moreover, these results can be useful in the diagnosis and treatment of this disease.

In another research performed by Karimi et al., out of 43 patients, only three tear samples (7\%) were positive for SARS-CoV-2, and one of the tear samples was positive in a patient with conjunctivitis [2]. In a study of 72 patients, only one tear sample positive was reported, in which the patient was a nurse [18]. Wu et al. said that among 38 patients with coronavirus, 12 patients had ocular symptoms. Among these 12 patients, only two patients had positive tear RT-PCR results [19]. The rate of positive yielded tear RT- PCR grew to $8 \%$ from previous studies.

In a study performed by Xie et al., two of the patients had positive RT-PCR results of conjunctival swab samples without any ocular manifestation [20]. In 102 patients in Zhang study, only two patients with conjunctivitis were identified and in one patient with conjunctivitis, tear SARS-COV-2 RT-PCR was positive [21].

In several other studies, no positive RT-PCR results were reported in the ocular samples.114 patients with COVID-19 pneumonia were investigated in Deng et al. research, and no ocular symptoms or signs were reported, and RT-PCR of conjunctival swabs samples was all negative [10].

The study of Dutescu RM et al. mentioned 28\% confirmation in tear samples, but they only had 18 patients and five patients had positive tear RT-PCR results. A total of 60 patients were analyzed, and eye involvement percentage has decreased in the larger study population. Moreover, multiple studies with different demographics from various geographical areas and a diverse spectrum of COVID-19 involvement can reveal more unknown aspects of this issue [22].

Another study of 108 patients with COVID-19 found that $69.4 \%$ of patients had mild ocular involvement, but it's not related to the nasal symptoms. [23]. Another study by Alexander C. et al. showed that none of the people who had a negative throat test had ocular involvement and therefore would not need further ocular examination if the throat test was not positive. We have found this cannot be completely true [24].

Ten patients had ocular manifestations in our study, including red-eye, secretion, conjunctivitis, and chemosis $(16 \%)$, and none of these patients had a positive tear test. There are limitations to diagnose the viral infection of ocular specimens by RT-PCR including small amounts of viral RNA in conjunctival secretions and sampling time which may lead to falsenegative reports on RT-PCR [25].

The number of positive tear samples was higher than in other studies which could be due to the high number of ICU samples or sampling time. As a result, doctors and nurses need to be safe from getting the disease through patients' eyes. For better information, future studies should be done with larger sample size. Moreover, by sampling in several stages of patients' eyes, the relationship between this infection and the duration of disease can be better understood. Besides, following the patients after recovery will obtain useful information about the possible complications of this disease on the eye and used it in treatment and prevention.

Author contributions (I) Conception and design: SeyedHashem Daryabari, Atieh Ayatollah; (II) Administrative support: Seyed-Hashem Daryabari, Farhad Adhami Moghadam; (III) the provision of study material or patients: Seyed-Hashem Daryabari,Ruhollah Dorostkar, Ali Bahramifar (IV) the collection and assembly of data: Seyed-Hashem Daryabari, Atieh Ayatollah; (V) Data analysis and interpretation: Hossein Aghamollaei, Atieh Ayatollah; (VI) Manuscript writing: All authors;

Funding No funding.

\section{Declarations}

Conflicts of interest No conflicts of interest. 


\section{References}

1. Zhu N, Zhang D, Wang W, Li X, Yang B, Song J, Zhao X, Huang B, Shi W, Lu R, Niu P (2020) A novel coronavirus from patients with pneumonia in China, 2019. New Engl J Med

2. Karimi S, Arabi A, Shahraki T, Safi S (2020) Detection of severe acute respiratory syndrome Coronavirus-2 in the tears of patients with Coronavirus disease 2019. Eye, 34:-4.

3. Chen Y, Liu Q, Guo D (2020) Emerging coronaviruses: genome structure, replication, and pathogenesis. J Med Virol 92(4):418-423

4. Sohrabi C, Alsafi Z, O’Neill N, Khan M, Kerwan A, AlJabir A, Iosifidis C, Agha R (2020) World Health Organization declares global emergency: A review of the 2019 novel coronavirus (COVID-19). Int J Surg 76: 71-76

5. Meduri A, Oliverio GW, Mancuso G, Giuffrida A, Guarneri C, Rullo EV, Nunnari G, Aragona P (2020) Ocular surface manifestation of COVID-19 and tear film analysis. Sci Rep 10:1-7.

6. Seah I, Agrawal R (2020) Can the coronavirus disease 2019 (COVID-19) affect the eyes? A review of coronaviruses and ocular implications in humans and animals. Ocul Immunol Inflamm 28(3):391-395

7. Loon SC, Teoh SCB, Oon LLE, Se-Thoe SY, Ling AE, Leo YS, Leong HN (2004) The severe acute respiratory syndrome coronavirus in tears. Br J Ophthalmol 88(7):861-863

8. Wan Y, Shang J, Graham R, Baric RS, Li F (2020) Receptor recognition by the novel coronavirus from Wuhan: an analysis based on decade-long structural studies of SARS coronavirus. J Virol 94(7):e00127-20.

9. Chen L, Deng C, Chen X, Zhang X, Chen B, Yu H, Qin, Y., Xiao, K., Zhang, H., Sun, X. (2020). Ocular manifestations and clinical characteristics of 534 cases of COVID-19 in China: a cross-sectional study. Acta Ophthalmol, 98:e951-e959

10. Lu CW, Liu XF, Jia ZF (2020) 2019-nCoV transmission through the ocular surface must not be ignored. Lancet (London, England), 395(10224): e39.

11. Iran's National Guideline for 2019-nCoV (2020), 2nd (edn). Available online at: https://firoozgar.iums.ac.ir/files/ baharestan/files/kesh.pdf. Accessed: 9 April 2021

12. National Health Commission of the people's republic of China (2020) The guideline on diagnosis and treatment of the novel coronavirus pneumonia; revised version of the 5 th edition. Accessed 8 Feb 2020

13. Grajewski RS, Rokohl AC, Becker M, Paulsen F, Heindl LM (2021) Malignancy going viral: ACE2 and TMPRSS2 expression in conjunctival neoplastic diseases. Ann Anat, 234:151661.
14. Grajewski RS, Rokohl AC, Becker M, Dewald F, Lehmann C, Fätkenheuer G, Cursiefen C, Klein F, Heindl LM (2021) A missing link between SARS-CoV-2 and the eye?: ACE2 expression on the ocular surface. J Med Virol 93(1):78-79

15. Luers JC, Rokohl AC, Loreck N, Wawer Matos PA, Augustin M, Dewald F, Heindl LM (2020) Olfactory and gustatory dysfunction in coronavirus disease 2019 (COVID19). Clin Infect Dis 71(16):2262-2264

16. Zhou Y, Zeng Y, Tong Y, Chen C (2020) Ophthalmologic evidence against the interpersonal transmission of 2019 novel coronavirus through conjunctiva. MedRxiv.

17. Holappa M, Vapaatalo H, Vaajanen A (2017) Many faces of renin-angiotensin system-focus on eye. Open Ophthalmol J 11:122

18. Sun CB, Wang YY, Liu GH, Liu Z (2020) Role of the eye in transmitting human coronavirus: what we know and what we do not know. Front Public Health 8:155

19. Wu P, Duan F, Luo C, Liu Q, Qu X, Liang L, Wu K (2020) Characteristics of ocular findings of patients with coronavirus disease 2019 (COVID-19) in Hubei Province, China. JAMA ophthalmol 138(5):575-578

20. Xie HT, Jiang SY, Xu KK, Liu X, Xu B, Wang L, Zhang MC (2020) SARS-CoV-2 in the ocular surface of COVID-19 patients. Eye Vision 7:1-3

21. Sun X, Zhang X, Chen X, Chen L, Deng C, Zou X, Yu H (2020) The infection evidence of SARS-COV-2 in ocular surface: a single-center cross-sectional study. MedRxiv.

22. Dutescu RM, Banasik P, Schildgen O, Schrage N, Uthoff D (2020) Detection of coronavirus in tear samples of hospitalized patients with confirmed SARS-CoV-2 from oropharyngeal swabs. Cornea.

23. Rokohl AC, Loreck N, Matos PAW, Zwingelberg S, Augustin M, Dewald F, Heindl LM (2020) More than loss of taste and smell: burning watering eyes in coronavirus disease 2019. Clin Microbiol Infect 26(11):1560-e5

24. Rokohl AC Grajewski RS, Matos PAW, Koch HL, Dewald F, Klein F, Heindl LM (2021) No secret hiding place? Absence of SARS-CoV-2 on the ocular surface of 1145 hospitalized patients in a pandemic area. Graefe's Arch Clin Exp Ophthalmol 259:1-4.

25. Deng C, Yang Y, Chen H, Chen W, Chen Z, Ma K, Wang J (2020) Ocular detection of SARS-CoV-2 in 114 cases of COVID-19 pneumonia in Wuhan, China: an observational study. In: China: an observational study (2/19/2020).

Publisher's Note Springer Nature remains neutral with regard to jurisdictional claims in published maps and institutional affiliations. 